\title{
A cura em psicanálise: efeitos orgânicos e subjetivos de uma análise
}

\author{
The cure in psychoanalysis: organics \\ and subjective effects of an analysis
}

\section{Fernanda Sanches de Sousa' ${ }^{1}$ (]) Marco Correa Leite ${ }^{2}$ (1)}

1Autora para correspondência. Centro Universitário Filadélfia (Londrina). Paraná, Brasil. psi.fersanches@gmail.com

${ }^{2}$ Centro Universitário Filadélfia (Londrina). Paraná, Brasil. mclmarco@hotmail.com

RESUMO | INTRODUÇÃO: O presente artigo é fruto de uma revisão bibliográfica com o intuito de evidenciar os efeitos do tratamento psicanalítico, não apenas enquanto algo da ordem do reportado pelos pacientes, mas também enquanto algo que pode ser mensurado a partir de alterações bioquímicas verificadas durante e após o tratamento psicanalítico. OBJETIVOS: Verificar se a psicanálise pode ter seus efeitos cientificamente mensuráveis para além dos relatos dos pacientes e dos analistas e, em último caso, apontar para uma possível eficácia do tratamento com relação às psicopatologias contemporâneas. MÉTODO: Pesquisa bibliográfica sistemática de artigos científicos, publicados de 2008 até a presente data, que demonstravam os efeitos verificáveis de uma análise nos pacientes, sejam alterações funcionais ou bioquímicas. RESULTADOS: Foram encontradas inúmeras evidências dos efeitos de um trabalho psicanalítico no decorrer do tratamento, e também, após o término do mesmo. CONCLUSÃO: Com este estudo foi possível verificar que a psicanálise é efetiva para uma série de transtornos mentais e que pode ser o tratamento padrão ouro, quando respeitados os devidos cuidados com relação à formação dos analistas. Novas pesquisas devem ser realizadas, fazendo um comparativo mais amplo entre a psicanálise e outras modalidades no campo da saúde mental.

PALAVRAS-CHAVE: Psicanálise. Saúde mental. Tratamento. Eficácia.
ABSTRACT | INTRODUCTION: This article results from a bibliographic review to highlight the effects of the psychoanalysis treatment, not only based on the issues reported by the patients but also in other outcomes measurable by biochemistry changes that are verified during and after the treatment. OBJECTIVES: To verify if psychoanalysis with its effects can be scientifically measured beyond the report of the patients and the analysts and, in the last case, to point out the efficacy of the treatment for contemporary psychopathology. METHODS: It was carried out a systematic literature review of referenced articles, considering the period from the year 2008 to current days, which aimed to demonstrate verifiable effects in the patients that were submitted to psychoanalysis, considering either functional or biochemistry changes. RESULTS: It was found that several evidences of the effects during the psychoanalytical process and also after the end of the treatment. CONCLUSION: With this work, it was possible to verify that psychoanalysis is an effective treatment for several mental disorders and can be a standard gold treatment once is respected the appropriate attention to the formation of the analysts. New researches must be done to compare psychoanalysis and other types of treatment in the mental health field.

KEYWORDS: Psychoanalysis. Mental health. Treatment. Efficacy. 


\section{Introdução}

Nos últimos anos, muitas pesquisas têm apontado resultados significativos da eficácia da psicanálise como tratamento para diversos tipos de transtornos mentais. Essas pesquisas colocam a psicanálise em um novo patamar no campo da saúde, pois que até então tem sido criticada pela ciência positivista como uma prática com pouco respaldo da comunidade científica. Com o avanço das ciências e em especial dos exames de neuroimagem é possível identificar os efeitos de um tratamento psicanalítico para além do relato do paciente e do psicanalista. Nos dias atuais, utilizandose das novas tecnologias disponíveis para tal, temos a comprovação dos efeitos do tratamento psicanalítico a partir de exames que demonstram significativas modificações estruturais e funcionais no cérebro e também na bioquímica corporal como um todo.

No presente artigo, foi realizada uma revisão bibliográfica sobre os efeitos mensuráveis do tratamento psicanalítico e pontuado de acordo com Freud que, em boa parte de sua obra, aponta a diferença radical entre a psicanálise e a psiquiatria, que segue o modelo biomédico de cunho biologicista. Foi também feita diferenciação da psicanálise de outros modelos terapêuticos a partir de seu método, sua ética e em especial de seu objetivo.

Para esta empreitada, foram analisados artigos publicados de 2008 até a presente data, tendo como referência central a obra produzida por Freud e Lacan, para orientação do que é uma análise, em que se difere da psiquiatria, da psicoterapia, e seu objetivo. Também foram usados alguns comentadores, em especial no tocante à formalização do percurso e da finalidade de uma análise, e no que diz respeito ao dispositivo do passe criado por Lacan desde a fundação de sua Escola, especialmente para verificar se a análise foi levada até seu fim.

Ao compreender que a psicanálise produz efeitos terapêuticos, mas que estes não são seus objetivos principais, sendo vistos pelos analistas desde Freud como secundários ao tratamento e, melhor dizendo, são efeitos que por vezes tendem a ser um empecilho para o tratamento. Por isso, foi necessário percorrer um longo caminho para diferenciar o que é uma psicanálise, seu método, seu objetivo e, principalmente, como verificar se o objetivo analítico, a despeito de todas as alterações orgânicas e, também, aquelas mudanças relatadas pelo paciente, foi atingido.
Em outras palavras, como verificar que uma análise chegou ao fim produzindo o que dela se espera, a saber: um analista da própria experiência como afirma Lacan (1964/1998)?

A partir deste momento, esse instrumento abordará os efeitos orgânicos de uma análise, as diferenças entre a psicanálise, as psicoterapias e a psiquiatria e, ao fim, o que o arcabouço teórico da psicanálise sustenta como possibilidade de verificar que o objetivo de uma análise foi alcançado para além dos efeitos ditos terapêuticos.

\section{A psicanálise cura?}

Em uma pesquisa publicada no "Journal of the American Medical Association", por Leichsenring e Rabung (2008) foi apresentada uma revisão bibliográfica de larga escala comparando 23 estudos envolvendo 1053 pacientes sobre as diferenças entre a psicanálise e outros tipos de tratamento no campo da saúde mental. Nesta meta-análise, ficou comprovado que o tratamento psicanalítico tem uma taxa significantemente maior de efetividade frente aos problemas relatados pelos pacientes, do que outros tipos de tratamentos psicoterápicos menos intensivos como, por exemplo, as psicoterapias breves. Os pesquisadores analisaram os artigos que tinham como objeto de estudo o acompanhamento de pacientes diagnosticados com diferentes transtornos mentais, dentre os quais, depressão severa, anorexia nervosa e transtorno da personalidade limítrofe - caracterizado por medo de abandono e surtos de desespero e carência. Segundo a conclusão dos autores, o tratamento psicanalítico demostrou efeitos significativos, e os pacientes gozavam de uma certa estabilidade, que aumentava significativamente entre o fim do tratamento e às posteriores avaliações realizadas.

Em outra pesquisa realizada, Leichsenring e Rabung (2011) examinaram os efeitos de uma psicoterapia psicanalítica de longo prazo (mínimo de 50 sessões ou 1 ano) com diferentes tipos de transtornos mentais. Como resultado da pesquisa, concluíram que o tratamento é mais efetivo e seus efeitos significativamente mais duradouros que outros tipos de tratamentos psicoterapêuticos de curto prazo como a psicoterapia breve. Embora este artigo não traga dados diferenciando a psicoterapia da psicanálise, é importante notar que em muitos países, inclusive 
no Brasil, ainda há muita confusão neste aspecto (esclarece-se melhor as diferenças mais à frente neste artigo). O que chama a atenção é que o método utilizado está dentro dos parâmetros do que se considera um tratamento psicanalítico de acordo com os pesquisadores.

Em 2012, foi publicado um extenso trabalho denominado "Psychodynamic Psychotherapy Research", um livro que traz 32 artigos de pesquisas em psicanálise articuladas com as neurociências. Em boa parte dos artigos encontrados no livro, há fortes evidências de que o tratamento psicanalítico tem sua eficácia passível de ser verificada, tanto quanto outros tratamentos no campo da saúde mental. No mesmo livro, é possível encontrar uma série de artigos interessantes que apontam os efeitos da psicanálise a partir de sólidas evidências empíricas.

$\mathrm{Na}$ introdução de "Psychodynamic Psychotherapy Research", Levy et al. (2012) afirmam que a psicanálise é um tratamento eficaz e que as pesquisas no campo da saúde mental têm corroborado as evidências de que sua aplicação tende a trazer muitos benefícios para além do problema relatado pelo paciente. Ao contrário de outros tipos de tratamentos focados na redução da sintomatologia e na manutenção de um suposto bem-estar, a psicanálise promove significativas modificações em toda a vida do paciente. Mudanças não apenas verificáveis na diminuição ou desaparecimento dos sintomas relatados pelos pacientes, mas que podem ser mensuradas em testes, exames laboratoriais e de neuroimagens. Para citar um exemplo, Lehtonen et al. Kuikka (2012), encontraram um aumento da concentração de serotonina em alguns pacientes, e em outros foi encontrado um aumento no número de receptores serotoninérgicos.

De acordo com Levy et al. (2012), as pesquisas que constam no livro trazem importantes evidências empíricas com relação ao resultado do tratamento. Neste sentido, para os autores, a psicanálise deveria ser recomendada como tratamento padrão para muitos tipos de transtornos mentais que são suscetíveis de serem tratados pelo método freudiano.
Ainda segundo Levy et al. (2012), foram encontradas evidências de que existe um subgrupo de pacientes com depressão maior, especialmente aqueles que mostram sinais de sensibilidade à rejeição e outras formas atípicas de sintomas, cujas respostas ao tratamento psicanalítico são refletidas em um aumento na ligação do transporte de serotonina e em alguns casos aumento dos receptores serotoninérgicos. No mesmo estudo, também se verificou que alguns pacientes com sintomas clássicos de depressão maior demostraram melhora clínica semelhante, mas nenhuma alteração na ligação do transporte de serotonina e também um aumento de receptores de serotonina após 6 meses análise. $O$ estudo também demonstrou, que no grupo tratado com antidepressivos inibidores seletivos da recaptação da serotonina, após os mesmos 6 meses de tratamento, não houve aumento dos receptores, embora houvesse alguma melhora no quadro clínico.

Com relação à melhora do quadro depressivo sem qualquer modificação passível de ser encontrada via exames de neuroimagens, isso pode se dar devido à depressão ser uma das psicopatologias que tem como causa múltiplos fatores. Um artigo publicado na revista Nature, decorrente da pesquisa realizada por Kennis et al. (2019) confirma a tese de que ainda não se tem dados significativos que possam comprovar que a depressão tem uma causalidade orgânica. No mesmo artigo, é possível verificar que as teorias que apostam no modelo da causalidade biológica carecem de evidências que possam direcionar não apenas ao encontro de uma causa como também um tratamento adequado para estes pacientes. Diante destas novas pesquisas, verificam-se a atualidade dos textos freudianos que apontam a causalidade das psicopatologias como uma série imbricada de ocorrências constitucionais orgânicas somadas aos acontecimentos históricos de cada um.

O pensamento freudiano para as psicopatologias, pode ser atualmente relacionado ao que é encontrado a partir das pesquisas no campo da epigenética e também das pesquisas focadas nas interações gene-ambiente ${ }^{1}$. No transtorno depressivo maior, por exemplo, tal como é descrito no DSM-V (O Manual de

\footnotetext{
1 Em uma nota de rodapé no texto "Sobre a dinâmica da transferência" Freud (1912, p. 107) escreve que os fenômenos psicopatológicos se produzem a partir de fatores inatos (constitucionais) e de fatores acidentais, que está relacionado com as experiências do indivíduo tanto no campo do Eu quanto na história de seus antepassados.
} 
Diagnóstico e Estatístico de Transtornos Mentais), em que não é possível encontrar um biomarcador específico para a causa da patologia, como apontado por Kennis et al. (2019). Seguindo esta linha de raciocínio, muito provavelmente, o problema da depressão é de ordem epigenética, ou seja, da interação do indivíduo com o meio, interação essa que pode causar uma série de efeitos no modo como uma determinada proteína é ou não sintetizada. Esta alteração da síntese proteica tem como efeito uma alteração fenotípica que pode produzir, consequentemente, o adoecimento ou a cura de determinada patologia.

Em nosso dia a dia clínico, consegue-se verificar esta questão por outro viés, não através de exames de neuroimagens, ou bioquímicos, mas através do relato dos pacientes que informam sobre a depressão irromper em determinado momento da vida do mesmo, por exemplo (mas não apenas), quando ele se dá conta de uma cena traumática. Essa interação do paciente com sua própria narrativa pode construir ou descontruir um quadro depressivo. Este achado clínico está de acordo com o que escreve Dunker (2021) ao afirmar que a depressão, embora não tenha uma origem/causa definida, pode ser tratada pela via da palavra, pelo método analítico e, mais ainda, faz efeito no corpo.

De acordo com Dunker (2021), a prática da psicanálise consiste em verificar todo o valor que a fala tem, na forma de uma narrativa do sujeito, tanto para a produção de uma determinada patologia, quanto para a sua cura. Pensar a questão da epigenética, é pensar o organismo sendo afetado por aquilo que causa enquanto sujeitos, a saber, de acordo com o ensino de Lacan (1953/1998): a linguagem.

Em artigo publicado no World Psychiatry, os pesquisadores Fonagy et al. (2015) realizaram um estudo controlado randomizado com 129 pacientes selecionados para o tratamento de depressão maior. Um dos critérios para escolha dos pacientes, era que eles deveriam ter passado já por pelo menos mais dois tipos de tratamento e não terem alcançado melhora significativa no quadro. Eles foram divididos em dois grupos distintos, o primeiro grupo foi conduzido para o tratamento psicanalítico em conjunto com o tratamento usual no Reino Unido seguindo o Guideline estabelecido para Depressão maior $(n=67)$ no mesmo país. O segundo Grupo beneficiou-se apenas do atendimento prescrito no Guideline (TAU) $(n=62)$. Todos os pacientes foram avaliados na entrada do tratamento,
6, 12 e 18 meses no decorrer do tratamento e também 24, 30 e 42 meses após findado o tratamento. Durante o tratamento não foi observada diferença significativa entre os dois grupos, no entanto, após o término do tratamento, após 42 meses, $44 \%$ dos pacientes tratados com psicanálise deixaram de ser enquadrados nos critérios de depressão maior, de acordo com o DSM-IV. Já para o grupo controle, apenas $10 \%$ foram beneficiados da mesma maneira.

A partir do que foi demonstrado até este momento, pode-se verificar que a psicanálise pode produzir a remissão do quadro depressivo. Pode-se dizer, ainda que com alguma cautela, que a psicanálise tem demonstrado que é possível, através do tratamento criado por Freud, a cura para a depressão em alguns casos. Se a psicanálise trabalha apenas com a fala e não tem nenhum outro tipo de interação com o paciente, se não esta interação discursiva, que veicula uma série de afetos que se desdobram para além do objetivo de uma terapia, cujo foco é a redução da sintomatologia, pode-se dizer que a cura, em psicanálise, é produto da experiência de fala em transferência conforme afirmam diversos autores que versam sobre esta temática desde Freud, passando por Lacan e posteriormente Dolto (2002), Nasio (2017), Dunker (2021), entre outros.

Para além dos quadros depressivos, mas ainda a respeito de uma das patologias que mais afetam os indivíduos em nosso mundo contemporâneo, segundo Dunker (2021), pode-se encontrar também na Síndrome do Pânico e nos Transtornos de Ansiedade alguns resultados interessantes quando os pacientes são submetidos à cura pela psicanálise.

No artigo “Estudo demonstra a eficácia da Psicoterapia Psicanalítica no tratamento do transtorno de Pânico: Implicações para pesquisa psicanalítica, teoria e prática" (Tradução nossa), de Busch et al. (2009), foram avaliados 21 pacientes diagnosticados com síndrome do pânico, o tratamento se fez por 24 sessões de psicoterapia durante 121 semanas. Após este período, mais de $40 \%$ dos pacientes tiveram redução nas pontuações da escala PDSS (Panic Disorder Severity Scale). Esta redução estava em conformidade com o relato dos pacientes, que afirmavam uma importante diminuição na sintomatologia característica dos quadros de depressão. Além disso, os pacientes demonstraram grande melhora nas funções psicossociais, na ansiedade relacionada ao pânico e na depressão quando esta aparecia enquanto comorbidade do 
transtorno de pânico que estava presente em 8 dos 21 pacientes avaliados.

Tendo em vista o exposto até o momento, não é possível mais afirmar que a psicanálise carece de evidências empíricas, ao menos não entre os que de fato se colocam como pesquisadores ou que se dizem de acordo com aquilo que convencionou-se chamar de "Prática Baseada em Evidências". As pesquisas têm demonstrado, como pode-se notar até o momento, que a psicanálise pode, e muito, quando se trata do alívio de uma sintomatologia independentemente do tipo de transtorno ou psicopatologia que o indivíduo padeça.

No entanto, é preciso esclarecer que a psicanálise não tem como objetivo e foco o mesmo que a psiquiatria e outros modelos terapêuticos. Mais adiante, esse instrumento irá discorrer sobre este ponto crucial, mas, a princípio, faz-se necessário pensar em algumas diferenças propostas por Freud (1905/2017) desde o início de sua prática que irão culminar com a impossibilidade de pensar a psicanálise como uma psicoterapia ou como uma abordagem psicológica como geralmente se escuta, tanto no meio universitário, quanto no discurso social vigente.

\section{Psicanálise versus Psiquiatria}

Tendo a ciência já comprovado, conforme os artigos supracitados, que a psicanálise é um tratamento possível para diversos tipos de transtornos mentais, segue-se ainda a necessidade de esclarecer que o que se trata na psicanálise, não é o mesmo que se trata na psiquiatria e em outros tipos de terapias, que tem como foco a supressão do sintoma relacionado à queixa do paciente.

Para a psicanálise, os sintomas que levam o paciente ao consultório, são antes de mais nada, uma questão da ordem da fala. No caso citado por Freud (1916/2014) na conferência "Psicanálise e Psiquiatria", uma senhora de 53 anos que sofria de "delírio de ciúmes" é o objeto de uma investigação que irá explicitar as diferenças entre a psicanálise e a psiquiatria.

Enquanto para a psiquiatria o sintoma que o paciente relata é experimetado como um sofrimento a ser evitado, devendo ser amenizado quando não for possível ser extirpado, para Freud (1916/2014), o sintoma diz alguma outra coisa, que o próprio paciente ignora.
Freud (1916/2014) faz uso desse exemplo para dizer que, pelo mecanismo de deslocamento, a senhora estava agindo de maneira que ela própria havia providenciado o desenrolar da história causadora de sua angústia, e com isso Freud mostra que a causa de seu ciúme nada tinha a ver com fatos da realidade, mas sim com um desejo inconsciente que havia surgido como uma ideia e que, por ser algo que iria contra a moral e os bons costumes (um desejo contrário ao Eu), esta ideia foi prontamente reprimida.

Nas palavras de Freud (1916/2014) “Ela própria nutria intensa paixão por um jovem, pelo próprio genro. Dessa paixão ela nada sabia, ou talvez soubesse um pouco." (p. 337). Ainda no mesmo parágrafo, ele continua: "Por se tratar de coisa monstruosa, impossível, tal paixão não podia tornar-se consciente; não obstante, ela seguiu existindo e exercendo forte pressão inconsciente." (p. 337).

É neste ponto que Freud (1916/2014) diferencia a psicanálise da psiquiatria. Enquanto a psicanálise ouve o paciente em sua individualidade e busca a causa da doença, a psiquiatria "toca superficialmente qualquer inferência acerca do conteúdo do delírio, e, ao apontar para hereditariedade, dá-nos uma etiologia geral e remota, em vez de indicar, primeiro, as causas mais especiais e próximas" (p. 341). Ainda no mesmo texto, verifica-se uma insistência em demonstrar as diferenças necessárias entre os dois campos do saber, não no sentido de se excluírem, mas talvez de se complementarem. Conforme afirma Freud (1916/2014) "Os senhores concordarão em que não há, na essência do trabalho psiquiátrico, nada que poderia se opor à pesquisa psicanalítica" (p. 341).

A medicação, quando administrada com parcimônia e receitada por um psiquiatra, pode ser útil em determinados casos, principalmente em se tratando de estabilizar pacientes que estão em situação crítica, conforme a avaliação da equipe de saúde mental. No entanto, a medicação por si só não produz mudanças efetivas no tocante à causalidade dos problemas. Pode-se dizer que a medicação, em alguns casos muito específicos, auxilia na melhoria da saúde mental dos pacientes, aliviando a sintomatologia. No entanto, conforme pesquisa publicada Berghout et al. (2010), os efeitos de uma análise geralmente persistem durante anos após findado o tratamento, o que geralmente não ocorre quando do uso de psicotrópicos. 
A psicanálise, em contrapartida, tende a escutar o paciente e busca encontrar, através da fala daquele que se queixa, e não do saber de quem escuta, a causa que, segundo Perez (2012), Freud encontrou nos processos psicodinâmicos inconscientes. Nesse sentido, a proposta do trabalho analítico só pode ser pensada a partir do tratamento individual.

O tratamento psicanalítico também se difere do tratamento preconizado pela psiquiatria pela impossibilidade de categorizar o paciente em determinada patologia. Na clínica, não se encontra dois neuróticos iguais, ou sequer com uma ideia, ou acontecimento similares que tenham desencadeado o transtorno mental. Freud em diversos momentos de sua obra afirma que nem sequer encontra-se um neurótico obsessivo "puro", por assim dizer. Inclusive, em seus artigos sobre a técnica, que datam de 1912 a 1914, ele adverte a todos que desejam exercer a função de analista que se deve ter muito cuidado quando se recebe um paciente, que é necessário ouvir com paciência e cautela pois é muito fácil errar no diagnóstico, em especial de pacientes graves. Mais uma vez, é preciso especificar que a psicanálise trabalha no um a um, no caso a caso, pois que, um mesmo acontecimento não tem força para causar determinada psicopatologia em indivíduos diferentes. Segundo Freud (1937/2017), o desencadeamento do adoecimento é fruto de uma conjunção de fatores filogenéticos, ontogenéticos e acidentais que concorrem para um acréscimo de energia em que a quantidade se torna insuportável ao aparelho psíquico, sendo experimentado pelo indivíduo como sofrimento.

Pode-se dizer então que a psicanálise trabalha rigorosamente com o caso a caso, com a escuta do sujeito que se produz em transferência entre aquele que sofre e fala de seu sofrimento a um outro que acolhe escutando sem julgamentos e direcionando o tratamento de forma imparcial. A este respeito é interessante dizer que, segundo Teixeira e Caldas (2017), enquanto na psiquiatria a escuta vai na tentativa de diagnosticar a partir de elementos encontrados na fala do paciente para enquadrá-lo em determinado roll de psicopatologias, para então tratar com a medicação adequada para o caso. Na psicanálise, a cura é o tratamento em si, sendo impossível de ser replicado para outro paciente.

A despeito das pesquisas realizadas que comprovam sua eficácia para um grande grupo de pacientes, conforme foi trabalhado até aqui, incluindo os casos de psicoses, adições, doenças psicossomáticas (casos em que preferencialmente se diagnostica e se medica sem que seja tratado o sujeito atravessado pelo sofrimento), Freud (1905/2017) chama a atenção para que resultados terapêuticos não devam ser o objetivo de uma análise. Além disso, faz alerta para que se evite o que nomeou de Furor Curandis principalmente entre os jovens analistas. Embora o analista experimente na sua análise pessoal, e também pelos casos clínicos atendidos no dia a dia, os efeitos terapêuticos que alcança e que são geralmente benéficos, ocorrendo com certa frequência em análise, a psicanálise deve ser dirigida a outro objetivo. Objetivo este que a diferencia metodologicamente e eticamente de outros modelos psicoterapêuticos. Sendo assim, qual o objetivo da psicanálise enquanto tratamento e quais são essas diferenças com relação às outras modalidades de tratamento no campo da saúde mental? A seguir, esse instrumento diferenciará a psicanálise das psicoterapias e, posteriormente, encaminhará para pensar o fim de análise em uma dupla perspectiva, a saber: o final do tratamento e também sua finalidade.

\section{Psicanálise ou Psicoterapia?}

Freud (1905/2017), em seu texto "Sobre Psicoterapia", começa dizendo o que é uma psicoterapia, suas origens e seus objetivos, os métodos utilizados por ele, suas descobertas, a hipnose e a catarse. Um leitor menos precavido pode até se confundir, caso não esteja com a devida atenção, não apenas no sentido que leitura vai ganhando, mas antes, se não lê a letra daquilo que está escrito. Ele enquadra a psicanálise dentro do roll das terapias, mas também a diferencia: "A partir de determinadas observações minhas, os senhores devem ter deduzido que o tratamento analítico possui algumas características que o mantém distante do ideal de uma terapia." (p. 69).

Freud, em toda a extensão de sua obra trabalha com o termo psicoterapia e terapia, mas jamais de uma forma a igualar sua ciência com as outras modalidades terapêuticas que se apresentavam, e se apresentam ainda hoje.

Fazendo uma comparação com os resultados obtidos por Huber et al. (2012) entre os efeitos de uma análise e os efeitos terapêuticos de terapias breves, por 
exemplo, Freud (1905/2017) já estava ciente quando escreveu: "...se com o procedimento mais trabalhoso e dispendioso tivermos resultados muito melhores que com tratamento breve e mais fácil, então apesar de tudo o primeiro se justifica. " (p. 70).

Ora, é possível pensar que os tratamentos breves, focados na sintomatologia, ou ainda na eliminação dos sintomas, podem ser utilizados quando necessário, mas isso não é uma análise, uma análise possui métodos e objetivos distintos.

Ainda no mesmo texto, Freud (1905/2017) dá uma direção sobre os pacientes para os quais ele indica o tratamento psicanalítico "A terapia psicanalítica foi criada a partir de e para doentes com incapacidade duradoura de viver, e o seu triunfo é que torna um número satisfatório deles capazes de viver a sua existência de forma duradoura. " (p. 71). Para fazer uma breve comparação, Fonagy et al. (2015) em sua pesquisa concluíram que $40 \%$ dos pacientes tratados com a psicanálise, quando já tiveram sido tratados, por pelo menos outras duas modalidades terapêuticas, tiveram remissão no quadro de depressão maior. Citando mais uma vez Freud (1905/2017): “...ali onde pouco se podia fazer com a psicoterapia analítica, pode-se afirmar tranquilamente que qualquer outro tratamento certamente não alcançaria absolutamente nada". (p. 71)

De 1905, praticamente o início do que Freud denominou a psicanálise, para 1937, há um texto fundamental para os dias de hoje, em que Freud delimita o que é, e o que pode a psicanálise.

De acordo com Freud (1937/2017) "Como se sabe, o objetivo do trabalho analítico é fazer com que o paciente volte a suspender (levantar) os recalques" (p. 366). Em diversos momentos de sua obra, Freud convoca sempre a pensar a psicanálise não como uma psicoterapia, que tende a curar sintomas, mas como outra coisa. Embora no processo os sintomas apareçam, desapareçam, migrem, se transformem, os ganhos neste aspecto são secundários e não o objetivo final.

Lacan (1964/1998), mas não apenas ele, se perguntava em seu ensino sobre qual seria o objetivo de uma análise e, em "Do trieb de Freud..." ele revela: "Qual a finalidade da análise, para além da terapêutica?
Impossível não a distinguir desta quando se trata de produzir um analista. " (p. 868). Lacan toca no cerne da questão. Uma análise deve ser sempre orientada para produzir um analista. Produzir um analista é submeter alguém a uma fala livre, o mais livre quanto for possível, e permitir com isso, que este que fala se espante, se surpreenda com aquilo que aparece, com isso que fala, com o "sujeito no sujeito, transcendente ao sujeito" (p. 438). Alguém que está advertido de que é habitado por algo além de si.

Para Freud(1937/2017) não era diferente, ele escreveu o seguinte: "O seu trabalho estará terminado quando trouxer para o aprendiz a convicção segura da existência do inconsciente, quando Ihe transmitir as auto percepções - normalmente indignas de crédito - ao aflorar o recalcado..." (p. 356).

Para Freud, e também para Lacan, uma análise deve ser sempre encaminhada para isso, suspender o recalque e testemunhar aquilo que jaz ali. Os efeitos do que irrompe no discurso, já não mais recalcado, mas devendo ser admitido pelo analisante, são sentidos não sem o corpo. Esta intrincada articulação em que se tem, de um lado o corpo e do outro a psique, composta das representações mentais é atravessada pela pulsão que não o faz sem deixar marcas. O corpo se modifica a partir dos efeitos da intervenção do analista. Suspender o recalque não é sem efeitos orgânicos, como já exposto nas pesquisas citadas neste artigo. $O$ analista, a princípio, é o produto de uma experiência analítica, não a pessoa, mas o sujeito que resulta de uma análise, mais precisamente, uma formação do Inconsciente.

A seguir, o texto mostrará como se dá uma experiência analítica, seus efeitos a partir da psicanálise, sua ética, método e seu objetivo.

\section{Ora, o que é e como é esta experiência analítica?}

Freud, em seus artigos técnicos ensina sobre a experiência da psicanálise, embora tenha relatado minuciosamente os processos, o método e o mecanismo de uma análise, ainda assim, não foi encontrada uma formalização teórica rigorosa que dê conta do que é uma análise. Basta ler em seus artigos sobre a técnica, quando ele compara a análise com o jogo de xadrez. 
Esta analogia leva a pensar que talvez, a psicanálise devesse ser mais conduzida pela subjetividade do analista do que pelo dispositivo teórico e técnico que ele inventara. Hoje, após muito ser produzido, sabe-se que a psicanálise pode ser pensada como a aplicação da teoria psicanalítica. O que seria aplicar a teoria? Qual teoria?

A entrada em análise não se dá de uma vez, Freud (1914/2017) em "Lembrar, repetir e perlaborar", nos mostra um percurso necessário, um antes, um durante e um depois. O que ele denominou de psicanálise é uma construção a partir do dispositivo clínico em que se encontram, a princípio duas pessoas, para que uma fale. Aquele que procura o analista ignora um saber próprio que o habita e convoca o outro a responder por ele. $\mathrm{O}$ analista por sua vez, ignora o que sabe da teoria para dar voz àquele que ignora o que sabe de si. Enquanto o analisante supõe um saber próprio a ele no analista, o analista supõe um sujeito de desejo no dizer do analisante.

Este jogo tem como regra apenas que o paciente diga tudo o que lhe vier à cabeça, sem restrições. Bom, isto faz com que em determinado momento, quando o analista está em jogo, o paciente comece a se dar conta de mais do que se supunha saber. Freud denomina o procedimento inicial, preliminar ao tratamento, de terapia de teste. Neste momento, o analisante vai construindo uma história a partir da narrativa que ele vai desenvolvendo na relação com o analista (Freud, 1937/2017). Esta construção, no entanto, ele insiste que é apenas o primeiro momento do trabalho. Nota-se, após uma análise rigorosa dos textos técnicos que, no ensino de Freud, há uma lacuna entre o início e o fim do tratamento. Freud (1937/2017) denomina de fim do tratamento quando o analisante se depara com o rochedo da castração e, ainda, quando o analisante não é mais sugestionável pelas intervenções do analista. É como se houvesse um momento na análise que, quando se chega lá, nada do que o analista diga pode modificar ou alterar a narrativa.

Será Jacques Lacan, quem irá trabalhar desde seus primeiros seminários com um maior rigor teórico sobre a formalização da psicanálise. Ao pensar seu retorno a Freud como uma releitura crítica dos textos freudianos, colocando a psicanálise para além do freudismo que a engessara dentro da Associação Psicanalítica Internacional, é possível ver que o trabalho de Lacan, do início ao fim, não foi outra coisa que não formalizar a psicanálise na medida do possível ali onde Freud não teve tempo ou elementos suficientes para tal.

Retomando da psiquiatria clássica as "Entrevistas Preliminares" para dizer que anteriormente ao tratamento psicanalítico é necessário saber se o paciente (ainda não analisante) tem condições de prosseguir com uma análise, Lacan, em diversos textos, principalmente a partir de 1964, formaliza também a entrada em análise, o uso do divã, o fim de análise e ainda inventa com seus colegas o dispositivo do passe para verificar este fim.

As entrevistas preliminares servem justamente ao que Freud denominou de terapia de teste, um tempo, um momento para que se definam alguns pontos, para que se construa uma demanda analítica, para que a transferência possa ser suficientemente estabelecida, entre outras condições prévias que, sem elas, o tratamento seria, talvez não inócuo, mas jamais da ordem de uma análise.

Para além da formalização do que é uma análise e seu percurso, este artigo limita-se a falar um pouco mais sobre o fim de análise enquanto término e também o objetivo de uma psicanálise no ensino de Lacan.

Lacan formaliza o fim de análise a partir de sua clínica. No primeiro tempo de seu ensino, em que empreendia seu retorno a Freud nos seminários na Sociedade Francesa de Psicanálise junto com os analistas e estudantes da referida associação, Lacan trabalha arduamente para desenvolver a teoria da travessia da fantasia como um fim possível de uma análise. Neste tempo, Lacan trabalhava com a noção de ponto de estofo, uma psicanálise que visava o sentido.

Neste primeiro momento, Lacan constrói a teoria da travessia da fantasia que pode muito bem ser encontrada na direção de tratamento proposta por Freud. É necessária uma breve explicação. Freud (1937/2017) não considerava um fim real para uma análise, em seus últimos textos, convocou os analistas a retornarem de tempos em tempos ao divã para fazer uma suposta limpeza em si para, com isso, estarem novamente aptos a sustentar o lugar de analista. Esta posição de Freud pode ser verificada em "A análise finita e a infinita", um artigo escrito em 1937 que encerra muitos aspectos do que seria uma psicanálise, 
seu objetivo e uma possibilidade de fim do trabalho analítico, sem uma formalização do que seria este fim, no sentido de possibilitar que seja passível de verificação a partir da teoria psicanalítica. Encontra-se no texto freudiano a ideia que uma análise teria fim quando o analisante deixasse de ir às sessões e também, quando o analista não tivesse mais condições de exercer a sugestão no paciente; o que causa certo estranhamento, visto que Freud se ocupara por toda sua vida para sustentar teoricamente a prática analítica. Com relação ao fim de análise, parece que muitos elementos ficaram faltando para que se produzisse uma teoria passível de ser clinicamente verificável.

Ocorre que, como dito anteriormente, Lacan reformaliza a psicanálise fazendo um retorno crítico a Freud e sustentando que a análise deva necessariamente ter um começo, um meio e um fim minimamente passíveis de serem verificados. Neste sentido Lacan, junto com seus colegas na Sociedade Francesa de Psicanálise, propuseram um fim de análise verificável. A partir das construções teóricas sobre a análise, o método e o que se verifica ao fim de um tratamento tem-se a construção da teoria da travessia da fantasia.

\section{De acordo com Zbrun (2014):}

A travessia da fantasia é a construção de um fragmento do real que entra no simbólico na forma de uma frase gramatical, que não pode ser explicada. Seu sentido não pode ser explicitado, seu valor não é semântico; ela vale por si mesma, embora seja capaz de reconstituir um pedaço do Real." (p. 93).

Ainda segundo Zbrun (2014), a construção que se obteria ao fim de uma análise é da ordem de uma frase gramatical, é o ponto de basta, o ponto de estofo, aquilo que sustenta o sujeito em sua fantasia mais primitiva, o que ancora o sujeito ao significante Mestre (S1) que é da ordem do recalque originário. Pode-se ver um exemplo disso na frase "Bate-se em uma criança", que Freud cuidadosamente trabalha em alguns de seus textos e que deve-se de retomar de tempos em tempos. A fantasia em si, para Lacan, é da ordem do S1, inamovível, puro significante, chegar lá, reconhecer-se ali, e a partir daí poder direcionar a própria vida, com isso que causa o sujeito e que era ignorado seria a primeira formulação bem construída de um fim de análise possível.
Avançando no tempo, já posteriormente à fundação de sua Escola, Lacan (1967/68) em seu seminário sobre $o$ ato analítico traz à tona uma questão muito pertinente a respeito do que se espera de um analista enquanto "ser". Se é possível pensar o ser do analista pela via da despredicatização do sujeito, da dessubjetivação do mesmo, em outras palavras: a destituição subjetiva. A travessia da fantasia se articula com a destituição subjetiva naquilo que é preciso atravessar o ponto de fixação sintomático que prende a uma modalidade muito específica de gozo na relação, com o Outro. Diante da pergunta "O que sou para ti?" A resposta, sintomaticamente produzida, fixa o sujeito em uma determinada posição imaginária que tenta tamponar o buraco do Outro. Atravessar a fantasia pode ser pensado como ir além da fantasia, da possibilidade de completude do outro, ir além de ser ou ter o falo, reconhecer a castração no Outro.

De acordo com Bastos (1997) "Enquanto Freud fica com a crença no inconsciente e o saber fazer com o sintoma, Lacan pretende que se avance na direção da queda da crença no Outro, e da consequente queda da crença fálica" (p. 101).

Em "Proposição..." Lacan (1967/68) vai direto ao ponto dizendo que o analista é aquele que passou pela experiência de ver naufragar todas as suas certezas, diante disso, a proposta é de se sustentar, não mais pela via de um Outro garantidor, mas a partir da articulação do sujeito em relação a seu desejo.

Avançando no tempo, mais precisamente no início da década de 70, Lacan começa a se apropriar do nó borromeano e realiza nova articulação da teoria. A travessia da fantasia enquanto possível fim de análise é repensada, nunca deixada de lado, mas vista por uma outra perspectiva. Conforme a teoria vai avançando, novos problemas vão surgindo e novas soluções vão sendo propostas. O problema da verificabilidade de um fim possível para o tratamento psicanalítico, repousa necessariamente na produção do analista. É certo que nem todos que chegam a atravessar a fantasia dão conta de conduzir uma análise; percebendo isso, Lacan e os membros da Escola Freudiana de Paris, desde 1964, estavam teorizando sobre a questão da verificabilidade do fim de análise e da construção de um dispositivo que possa garantir a partir do relato do analisante que o analisante chegou lá. Em outras palavras, que a análise produziu aquilo que dela se espera: a destituição subjetiva. 
Surge então, concomitantemente com a criação da Escola Freudiana de Paris, o germe de um dispositivo chamado de dispositivo do passe. Este dispositivo tinha como pressuposto não apenas verificar o momento em que se daria o fim de análise, mas produzir uma doutrina sobre isso que fosse passível de ser verificado em cada caso. Curiosa questão do passe, que busca a partir do geral, ler o singular e único da experiência de cada um.

Conforme Soler (1995) em "Variáveis do fim da análise", o fim de análise é um problema de equação a ser resolvido. Uma equação que ao final produz um sujeito transformado. Este sujeito transformado é aquilo que permite pensar a passagem de analisante a analista. No entanto, e isso tem que ficar muito claro, analista não é quem atende em consultório, mas um significante inventado por Freud para dizer de alguém que de alguma maneira levou a sua análise até o fim. $O$ analista é aquele que passou pelo processo de análise e que em determinado momento solucionou sua equação, resolveu de alguma maneira o mistério relacionado com o desejo que o habita e que, no início da análise só sabia dele pelas formações do inconsciente que davam notícia e nada mais. Uma vez que isso está resolvido para ele, pode acompanhar um outro neste percurso. Importante que se saiba disso, a psicanálise produz um analista; o seu fim e o passe enquanto dispositivo de Escola testemunham isso.

Como afirma Zbrun (2014), é possível pensar em um momento do passe e um dispositivo do passe. $\mathrm{O}$ dispositivo do Passe é o dispositivo da Escola em que os analistas que desejam tornarem-se AE (Analistas da Escola) pedem a escola para entrar no dispositivo. Já o momento do passe, embora esteja também articulado com a doutrina construída pela escola, ocorre durante a análise verificável pela destituição subjetiva que pode ser encontrada a partir do próprio analisante nas sessões.

Mas o que o passe verifica afinal?

A partir da década de 70, mais precisamente no ano de seu vigésimo seminário, vemos que Lacan trabalha uma nova concepção do fim de análise que engloba a travessia da fantasia, no entanto, não se restringe a ela.
Com o auxílio do nó borromeano, Lacan começa a produzir novidades no campo da compreensão do que seria um percurso de análise de uma forma um pouco mais abrangente. O próprio nó borromeano, não apenas ele, mas todo o estudo da linguística, topologia, matemas, serve para que possamos dar conta, teoricamente do que acontece na experiência clínica. Utilizando-se do nó borromeano é possível uma nova leitura de muitos dos elementos, até então, impossíveis de serem compreendidos por outra via. Para dar um bom exemplo, peguemos o registro do Real. Somente a partir da teoria dos nós e das elucubrações pela via das cordinhas e barbantes é que ele pode ser teoricamente positivado.

Para ir direto ao ponto, Lacan retoma a grafia Sinthoma com TH para escrever algo da ordem que é esperado que o analisante produza em análise, marcando a passagem de analisante a analista. Lacan (1975-1976/2017), ao se utilizar do Sinthoma com TH, está realizando uma somatória do sintoma com a fantasia. Com a passagem de analisante a analista, não se trata mais de explicar o sintoma pela via de um dizer sem sentido, mas de produzir, com efeito, uma transmutação no sujeito que dê conta do real em jogo, ou ainda, de jogar com o real em cena. Não se trata de uma nova teoria sobre o fim de análise, mas uma tentativa a mais de dar conta do que já ocorria, mais um modo de tentar dizer o que o próprio Lacan em seus seminários, afirmava ser impossível: transmitir a psicanálise.

Para finalizar, quando surge a ideia do Sinthoma como um quarto nó, torna-se possível escrever, ou melhor, desenhar a teoria da derrocada do grande Outro. A queda do Outro como momento necessário de uma análise ocorre concomitantemente com a amarração do $4^{\circ}$ nó. Aqui tem-se o $4^{\circ}$ nó que permite que o sujeito prescinda do nome do pai para, a partir daí servir-se dele.

O $4^{\circ}$ nó, chamado de Sinthome, então, é o que passa a estabilizar a estrutura. Este $4^{\circ}$ nó é efeito do tratamento psicanalítico, resultado de um percurso de análise, não existe fora dela. Aqui tem-se, ao menos por hoje, o objetivo de uma psicanálise. A todos que desejam ocupar este lugar de analista, custe o que custar, há que se chegar lá. 


\section{Considerações finais}

Considerou-se, durante o percurso deste trabalho, a delimitação dos efeitos verificáveis do tratamento psicanalítico. Em um primeiro momento, foi realizado um trabalho de resgate de uma série de artigos científicos publicados que atestam os efeitos na bioquímica corporal. Em um segundo momento, o estudo avançou para diferenciar a psicanálise da psiquiatria. Este ponto é de extrema importância, pois nos permite verificar que a psicanálise e a psiquiatria incidem sobre o corpo a partir de vetores opostos. Enquanto a psicanálise opera sobre o corpo pela via da palavra, a psiquiatria tende a operar no corpo para que, na palavra do paciente, algo possa aparecer no sentido de um relato de bem-estar. No terceiro ponto abordado neste artigo, pode-se ver com clareza que a psicanálise não pode ser confundida com as chamadas psicoterapias, visto que seu objetivo, seu método e mais particularmente o lugar que o analista ocupa é diferente do lugar que o terapeuta irá ocupar durante e após o tratamento com o paciente.

A questão que foi proposta do início ao fim desta pesquisa foi de poder encontrar elementos que permitam associar às alterações bioquímicas no corpo com o que Lacan propôs como fim de análise. Compreendese, no entanto, que, embora dimensões distintas do ser humano, estas dimensões não estão dissociadas. A dimensão do corpo orgânico, e a dimensão do corpo palavra, pode ser encontrada em 1914 quando Freud escreve em "A Pulsão e seus destinos" como articulados e impossível de pensá-los isoladamente. Neste sentido, não foi possível verificar um elemento único que, ao ser encontrado no corpo poderia dizer de um fim de análise, e tão pouco foi encontrada na teoria proposta por Lacan do fim de análise, algo que pudesse verificar no corpo como os efeitos de um fim de análise.

Fato é que as pesquisas voltadas à eficácia do tratamento em psicanálise estão ocorrendo de uma forma mais sistemática do que vinham sendo feitas até então. Isso dá uma margem para deixar esta questão ainda em suspensa. Ora, não é porque ainda não foi encontrado que este elo não exista e, se ele não existir, será preciso criá-lo na forma de apreender teoricamente o que se verifica nos corpos que se submetem à cura pela palavra.

\section{Contribuições dos autores}

Ambos os autores contribuíram na concepção, escrita e aprovação final do relato.

\section{Conflitos de interesses}

Nenhum conflito financeiro, legal ou político envolvendo terceiros (governo, empresas e fundações privadas, etc.) foi declarado para nenhum aspecto do trabalho submetido (incluindo, mas não se limitando a subvenções e financiamentos, participação em conselho consultivo, desenho de estudo, preparação de manuscrito, análise estatística, etc.).

\section{Referências}

American Psychiatric Association. (2014). Manual diagnóstico e estatístico de transtornos mentais: DSM-5. Artmed.

Bastos, R. F. (1997). Sobre o final de análise. In Revista Internacional: a lacaniana. Companhia de Freud.

Berghout, C. C., Zevalkink, J., \& Roijen, L. H. (2010). A costutility analysis of psychoanalysis versus psychoanalytic psychotherapy [Um custo-utilidade análise da psicanálise versus psicoterapia psicanalítica]. International journal of technology assessment in health care, 26(1), 3-10. https:// doi.org/10.1017/s0266462309990791

Busch, F. N., Milrod, B. L., \& Sandberg, L. S. (2009). A Study Demonstrating Efficacy of a Psychoanalytic Psychotherapy for Panic Disorder: Implications for Psychoanalytic Research, Theory, and Practice [Demonstrando a eficácia de uma Psicoterapia Psicanalítica para o Distúrbio do Pânico: Implicações para a Pesquisa Psicanalítica, Teoria e Prática]. Journal of the American Psychoanalytic Association, 57(1), 131-148. https://dx.doi. org/10.1177\%2F0003065108329677

Dolto, F. (2002). Tudo é Linguagem. Martins Fontes.

Dunker, C. (2021). Uma Biografia da Depressão. Planeta.

Fonagy, P., Rost, F., Carlyle, J., Mcpherson, S., Thomas, R., Fearon, R. M. P., Goldberg, D., \& Taylor, D. (2015). Pragmatic randomized controlled trial of long-term psychoanalytic psychotherapy for treatment-resistant depression: the Tavistock Adult Depression Study (TADS) [Pragmático ensaio controlado randomizado de psicoterapia psicanalítica de longo prazo para depressão resistente ao tratamento: o Estudo da Depressão Adulta Tavistock (TADS)]. World Psychiatry, 14(3), 312-21. https:// doi.org/10.1002/wps.20267 
Freud, S. (2017). Fundamentos da clínica psicanalítica. Autêntica. (Trabalhos originais publicados em 1905, 1912, 1914 e 1937)

Freud, S. (1916-1917/2014). Obras Completas (Vol. 13). Cia. das Letras

Huber, D., Zimmermann, J., Henrich, G., \& Klug, G. (2012). Comparison of cognitive-behaviour therapy with psychoanalytic and psychodynamic therapy for depressed patients - A three-year follow-up study [Comparação de terapia cognitiva-comportamental com terapia psicanalítica e psicodinâmica para pacientes deprimidos Um estudo de acompanhamento de três anos]. Zeitschrift für Psychosomatische Medizin und Psychotherapie, 58, 299316. https://doi.org/10.13109/zptm.2012.58.3.299

Kennis, M., Gerritsen, L., Dalen, M. V., Williams, A., Cuijpers, P., \& Bockting, C. (2020). Prospective biomarkers of major depressive disorder: a systematic review and meta-analysis [Biomarcadores prospectivos de grandes desordens depressivas: uma revisão sistemática e metaanálise]. Molecular Psychiatry, 25, 321-338. https://doi. org/10.1038/s41380-019-0585-z

Lacan, J. (1998). Escritos. Zahar. (Trabalhos originalmente publicados em 1953, 1957 e 1964)

Lacan, J. (2003). Outros escritos (V. Ribeiro, Trad.). Zahar. (Trabalho originalmente publicado em 1967)

Lacan, J. (1967/68). O ato psicanalítico: Seminário 1967-1968. Escola de Estudos Psicanalíticos.

Lacan, J. (2007). O Seminário, livro 23: O Sinthoma. Zahar. (Trabalho original publicado em 1975/1976)
Lehtonen, J., Tihonen, J., Joensuu, M. M. O., Lehto, S. M., Ahola, P. A., Saarinen, P. I., Valkonen-Korhonen M., Tolmunem, T., \& Kuikka, J. T. (2012). Toward molecular psychotherapy of depression? [Rumo a psicoterapia molecular da depressão]. In R. Levy, J. Alonso, \& H. Kãchele (Eds). Psychodynamic psychotherapy research: Evidence-based practice and practice-based evidence. Humana Press.

Leichsenring, F., \& Rabung, S. (2008). The effectiveness of longtermpsychodynamic psychotherapy: A meta-analysis [A eficácia da longa psicoterapia termpsicodinâmica: Uma meta-análise]. Journal of the American Medical Association, 300(13), 1551-1565. https://doi.org/10.1001/ jama.300.13.1551

Leichsenring, F., \& Rabung, S. (2011). Long-term psychodynamic psychotherapy in complex mental disorders: update of a meta-analysis [Psicodinâmica a longo prazo psicoterapia em distúrbios mentais complexos: atualização de uma meta-análise]. The British journal of psychiatry: the journal of mental science, 199(1), 15-22. https://doi.org/10.1192/ bjp.bp.110.082776

Levy, R. A., Ablon, J. S., \& Kächele, H. (Eds.). (2012). Psychodynamic psychotherapy research: Evidence-based practice and practice-based evidence. Humana Press.

Nasio, J. D. (2017). Sim, a psicanálise cura (E. Aguiar, Trad.) Zahar.

Perez, D. O. (2012). O Inconsciente: onde mora o desejo. Civilização Brasileira.

Soler, C. (1995). Variáveis do fim da análise. Papirus.

Teixeira, A., \& Caldas, H. (Orgs.). (2017). Psicopatologia lacaniana. Autêntica.

Zbrun, M. (2014). A formação do analista. KBR. 